\title{
The two-step to two-tier
}

1954

Doctor: "Your son needs an appendectomy. Do you have \$100?"

\section{4}

Doctor: "Yes, MRI will detect breast cancer earlier than mammography, but it isn't covered by medicare.

Patient: "No problem — I'Il pay for it."

Doctor: "Sorry, you can't have it even if you can pay for it."

$\mathrm{R}$ unning up to his highly publicized meeting with the premiers, Prime Minister Martin has announced another \$13 billion in health care funding in an attempt "to inject a sense of confidence back into the minds of Canadians on our public health care." But will an extra $\$ 13$ billion (over 5 years) restore confidence in a national health care system that already falls $\$ 100$ billion short of what would be needed to match US per capita spending?

We hear of Canadians who have sought care in the United States for investigation of metastatic lung cancer (with PET scans and targeted radiotherapy), who have paid for genetic testing of newborns to screen for multiple congenital diseases, who have spent hundreds of thousands of dollars for interferon B in the hope of slowing the progress of multiple sclerosis, or who have paid for expensive imaging in private clinics. Of total Canadian expenditures on health, about $30 \%$ are paid for privately. The fact is that we already have two-tiered health care in Canada.

Proponents of universal health insurance say that the first tier - core insured services - includes all or almost all diagnostic procedures and treatments that are medically necessary, while the second tier - those paid out of pocket — is almost all of minimal value.

If Mr. Martin is to keep his promise, he will have to do more than offer additional funding, which will never be enough in any case. He will have to convince the public that the medical and diagnostic services not available in Canada are of trivial or no importance - that seeking such care is but a folly of the wealthy or a desperate attempt by the severely ill to forestall the inevitable. A tough sell.

Or he will have to convince Canadians, particularly those who are not poor, that equity is more important than efficacy, and that whatever the health care opportunities available to the rich, they must forgo those that cannot be afforded by the state for everyone. Difficult, but not impossible.
Or he will have to admit that we have a two-tiered health care system in Canada: the public basket of services that meets predefined efficacy standards (currently about $\$ 50000$ per quality-adjusted life year $)^{2}$ and a supplementary private basket for those who can afford to purchase other services. Reality health care.

We favour the third option. To maintain the insured basket we will have to carefully (and promptly) evaluate new interventions and make a judgement about efficacy, even and most often in the absence of the hard evidence of randomized trials. To fund these additions to the public basket, while maintaining health care expenditures at some reasonable level of national and provincial spending, we must simultaneously apply the same methods to evaluate what that basket already contains and begin to deinsure some items. The Canadian Coordinating Office for Health Technology Assessment ought to play a lead role here, but it will have to be more rigorous, move more quickly and, above all, incorporate public consultation and public disclosure of its activities into the process. Equity is a social value and so, in the end, is efficacy.

But more than these changes to the assessment of what gets covered, we need to have a public debate and some frank discussion among our politicians. Not a debate about how much money can be thrown at the problem, but one about the importance of equity and the nuances and limits of efficacy. The continuing development of new diagnostic procedures and therapies (many emerging from the "genomification" of medicine) will test our current resolve to maintain equity. We will have to recognize that some people - those with money - will be able to purchase additional services, and we should make way for this possibility. But we should put equity just slightly ahead of efficacy. To accomplish this other than on the tiresome battlefield of political and economic rhetoric, we will need a continuous flow of information about the benefits and costs, as well as open and continuing discussion about the definition of the public basket. - CMAf

\section{References}

1. Laghi B. Dosanjh emphasizes accountability. The Globe and Mail [Toronto] 2004 Jul 22;Sect A:4.

2. Laupacis A, Feeny D, Detsky AS, Tugwell PX. How attractive does a new technology have to be to warrant adoption and utilization? Tentative guidelines for using clinical and economic evaluations. CMAF 1992;146(4):473-81. 